\title{
BMJ Open Risk and severity of herpes zoster in patients with rheumatoid arthritis receiving different immunosuppressive medications: a case-control study in Asia
}

Tsai-Ling Liao, ${ }^{1,2}$ Yi-Ming Chen, ${ }^{1,2,3,4}$ Hung-Jen Liu, ${ }^{2}$ Der-Yuan Chen ${ }^{2,3,4,5,6}$

To cite: Liao T-L, Chen Y-M, Liu H-J, et al. Risk and severity of herpes zoster in patients with rheumatoid arthritis receiving different immunosuppressive medications: a case-control study in Asia. BMJ Open 2017;7:e014032.

doi:10.1136/bmjopen-2016014032

- Prepublication history and additional material is available. To view please visit the journal (http://dx.doi.org/ 10.1136/bmjopen-2016014032).

Received 25 August 2016 Revised 10 November 2016 Accepted 30 November 2016

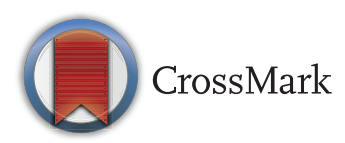

For numbered affiliations see end of article.

Correspondence to Dr Der-Yuan Chen; dychen@vghtc.gov.tw

\section{ABSTRACT}

Objective: Increasing evidence indicates that the risk of herpes zoster $(\mathrm{HZ})$ is elevated in rheumatoid arthritis (RA). Little is known about the epidemiology of $\mathrm{HZ}$ in patients with RA in Asia. The aim of this study was to determine the risk factors and outcomes of $\mathrm{HZ}$ among patients with RA.

Design: A case-control study.

Setting: A medical centre in Asia.

Participants: A total of 9025 newly diagnosed and eligible patients with RA (International Classification of Diseases, Ninth Revision, Clinical Modification (ICD-9CM) codes 714.0) during the period 2001-2014. Among them, 275 (3.05\%) were newly diagnosed with HZ (ICD-9-CM code 053.0) after the RA identification. As the control group, patients with $\mathrm{RA}$ without $\mathrm{HZ}$ were matched for age, gender and RA disease duration at the time of $\mathrm{HZ}$ infection with the $\mathrm{RA}-\mathrm{HZ}$ case group at a ratio of $4: 1$, and a total of 1100 control subjects were selected.

Outcome measures: We estimated ORs using conditional logistic regression to investigate the risk and severity of $\mathrm{HZ}$ among patients with $\mathrm{RA}$ receiving different immunosuppressive medications.

Results: Exposure to corticosteroids ( $\geq 10 \mathrm{mg} /$ day adjusted $\mathrm{OR}(\mathrm{aOR})=2.30,95 \% \mathrm{Cl} 1.25$ to 4.22 , $\mathrm{p}=0.01$ ), anti-tumour necrosis factor biologicals (aOR=2.07, 95\% Cl 1.34 to 3.19, p=0.001) and conventional synthetic disease-modifying antirheumatic drugs (methotrexate $(\mathrm{aOR}=1.98,95 \% \mathrm{Cl}$ 1.43 to 2.76, $\mathrm{p}<0.001$ ) and hydroxychloroquine (aOR=1.95, 95\% Cl 1.39 to 2.73, $p<0.001)$ ) was associated with an increased $\mathrm{HZ}$ risk in patients with RA. The association between the use of corticosteroids and $\mathrm{HZ}$ risk was dose-dependent ( $\left.p_{\text {trend }}<0.001\right)$. Timeto-HZ diagnosis among patients with RA receiving biological medications was significantly shorter than that in patients not receiving biological medications. A higher proportion of severe $\mathrm{HZ}$ and ophthalmic involvement was found in patients with RA receiving biologicals.

Conclusions: There was an increased risk of $\mathrm{HZ}$ in patients with RA taking specific immunosuppressive medication. Biologicals used were associated with

\section{Strengths and limitations of this study}

- This is the first case-control study to investigate an association between immunosuppressive drugs and herpes zoster ( $\mathrm{HZ}$ ) among patients with rheumatoid arthritis (RA) in Asia and the relationship between biologicals and severe $\mathrm{HZ}$.

- The use of long-term medical records: a 14-year follow-up period (2001-2014) enhanced the statistical power and accuracy of this study.

- The present study was conducted at a single medical centre and cannot reflect the complete characteristics of $\mathrm{HZ}$ in patients with $\mathrm{RA}$.

- The matched control cohort may have a selection bias. Nevertheless, we analysed data from a clinical information database and reviewed medical care records to identify patients with RA with $\mathrm{HZ}$.

severe $\mathrm{HZ}$ occurrence. Therefore, it is important to closely monitor and prevent severe $\mathrm{HZ}$ complications during specific immunosuppressive therapy.

\section{INTRODUCTION}

Herpes zoster (HZ) is a significant global health burden and results from reactivation of the latent varicella-zoster virus (VZV) within the sensory ganglia. ${ }^{1}$ Approximately $50 \%$ of persons living until the age of 85 years will develop $\mathrm{HZ}^{2}$ Ageing, female gender, ethnicity and depression were potential risk factors for $\mathrm{HZ}^{3}$ In addition, cellular immune dysfunction in certain diseases (eg, HIV infection and non-Hodgkin's lymphomas) is another factor triggering $\mathrm{HZ}^{4}$

Complications occur in almost half of the older persons with $\mathrm{HZ}$, including postherpetic neuralgia $(\mathrm{PHN})$, ophthalmic HZ, meningoencephalitis and secondary bacterial infection. ${ }^{5}$ PHN is the most common 
debilitating complication, a neuropathic pain syndrome that persists or develops after the dermatomal lesions have cured. ${ }^{6}$ PHN may impair the elderly patient's functional status by interfering with basic activities of daily life, resulting in an increased annual medical care cost. ${ }^{7}$ In addition, ocular nerve and other organ involvement with $\mathrm{HZ}$ may occur, often with severe sequelae. ${ }^{6}$

The Consortium of Rheumatology Researchers of North America registry data showed that VZV infection was the most frequent opportunistic infection in patients with rheumatoid arthritis (RA). ${ }^{8}$ Several studies in western countries demonstrated that patients with RA have an increased risk of $\mathrm{HZ}$ compared with the general population, which may be due to RA-related immune dysfunction or the immunosuppressive effects of therapeutic agents. ${ }^{9-12}$ Among patients with RA in the USA or Europe, those treated with anti-tumour necrosis factor (anti-TNF) biologicals, disease-modifying antirheumatic drugs and/or corticosteroids appeared to be at higher risk. ${ }^{11-15}$ The HZ incidence was higher in Asia (Japan: 4.15 per 1000 person-years; Taiwan: 4.89-5.67 per 1000 person-years) than in the USA (3.2-3.7 per 1000 person-years) and Europe (3.7 per 1000 personyears) ${ }^{16}$ In Japan, the HZ incidence in patients with RA was higher than that in the general population $(9.1 \mathrm{vs}$ 4.15 per 1000 person-years). ${ }^{17}$ However, the association between $\mathrm{HZ}$ and immunosuppressive medications in Asian patients with RA is still uncertain and little is known about clinical outcomes of $\mathrm{HZ}$ in patients with RA after treatment with different immunosuppressive medications. Therefore, we conducted a case-control study using a medical clinical information database to analyse the epidemiology, risk factors and outcomes of $\mathrm{HZ}$ in patients with RA with different immunosuppressive medications admitted to one medical centre in Taiwan during the period 2001-2014.

\section{METHODS}

Study setting, patients and data source

This case-control study was conducted at Taichung Veterans General Hospital (TCVGH), a medical centre in Taiwan. We searched the clinical database in accordance with case definitions to identify newly diagnosed and eligible patients with RA with $\mathrm{HZ}$ during the period January 2001 to December 2014. As the control group, patients with RA without $\mathrm{HZ}$ were matched for age, gender and RA disease duration at the time of $\mathrm{HZ}$ infection with the RA-HZ case group at a ratio of $4: 1$. The $\mathrm{HZ}$ infection date was in the index date for cases and their matched controls. Comorbidities and medication use were measured during the 365-day period prior to the index date. ${ }^{15}$ We evaluated clinical symptoms, outcomes, complications and medication used by reviewing the medical records of patients with RA with $\mathrm{HZ}$ and control cohorts. The data from the patient records/ information were forms of secondary information that were de-identified in an anonymous format prior to analysis. This study was conducted in compliance with the Declaration of Helsinki, has been approved by the Institutional Review Board of TCVGH (CE15001B) and the requirement of patient informed consent was waived. The methods were carried out in accordance with the approved guidelines.

\section{Definitions}

The identification of patients with different diseases in this study was primarily done using the International Classification of Diseases, Ninth Revision, Clinical Modification (ICD-9-CM) codes. The diagnosis of RA (ICD-9-CM codes 714.0) was made according to the 1987 American College of Rheumatology criteria ${ }^{18}$ and on more than one occasion in either the inpatient or outpatient record. The criteria were verified by using the National Health Insurance Research Database's Registry of Catastrophic Illness Patient Database (RCIPD). Patients with RA started biological therapy according to the guidelines of the British Society for Rheumatology. ${ }^{19}{ }^{20}$ The ICD-9-CM code of HZ was 053.0. The diagnosis of $\mathrm{HZ}$ was required to have been made after the RA identification index date. Baseline clinical HZ outcome measures (eg, hospitalisation, complication, death) were obtained within 6 months or longer from the initial HZ diagnosis index date. The definition of each comorbidity was based on the ICD-9-CM codes, including hypertension (HT, ICD-9-CM code 401.9), diabetes mellitus (DM, ICD-9-CM code 250), chronic kidney disease (CKD, ICD-9-CM code 585) and HIV disease (ICD-9-CM codes 042-044).

In this study, RA treatments were subdivided into three medication groups in accordance with the immunosuppressive drugs used: (1) anti-TNF biologicals, including adalimumab, etanercept and golimumab; (2) non-anti-TNF biologicals, including rituximab, tocilizumab and abatacept; (3) non-biologicals, including corticosteroids, hydroxychloroquine, sulfasalazine, methotrexate, leflunomide and non-steroid anti-inflammatory drugs. Immunosuppressive medication exposure analysis was conducted to study the drugs-used status before 365 days of the initial HZ diagnosis index date. ${ }^{15}$ For examining anti-TNF use, current use was defined as end of exposure $\leq 6$ months prior to the index date. ${ }^{21}$ For infused biological agents (eg, abatacept, rituximab and tocilizumab), we assigned exposure as 30 days for abatacept and tocilizumab, and 180 days for rituximab, based on the recommended dosing frequency. Patients using oral corticosteroids in the 90 days prior to the index date were categorised as baseline corticosteroid users. ${ }^{15}$ For all baseline corticosteroid users, we calculated a mean daily dose of prednisone equivalents in the 6 months prior to the index date. ${ }^{15}$ Severe HZ was defined as the requirement for intravenous antiviral treatment, or ophthalmic HZ. The study end point was defined as the onset of new $\mathrm{HZ}$ during the 14-year follow-up period (2001-2014). 


\section{Statistical analysis}

The data are presented as the means \pm SDs for the continuous variables, and proportions for the categorical variables. Descriptive statistics were used to analyse the patients' demographic and clinical characteristics. Student's t test and the $\chi^{2}$ test were used for univariate comparisons when appropriate. A p value of $<0.05$ was considered statistically significant. We used conditional logistic regression to estimate the crude and adjusted ORs and 95\% CIs to quantify associations between $\mathrm{HZ}$ and exposure to specific immunosuppressive drugs. The multivariable model was adjusted for covariates possibly associated with $\mathrm{HZ}$, including other immunosuppressive medication use and comorbidities (eg, HT, CKD and DM). A time-to-event analysis was performed using the log-rank test. Analyses were performed using the SPSS (IBM SPSS V.22.0; International Business Machines Corp, New York, USA). All tests were two-tailed with a type 1 error $(\alpha)$ rate of $5 \%$.

\section{RESULTS}

\section{Characteristics of study cohort}

A total of 9025 newly diagnosed and eligible patients with RA were identified at TCVGH during the period
2001-2014. Among them, 275 (3.05\%) were newly diagnosed with $\mathrm{HZ}$ after the RA identification. To evaluate the risk of $\mathrm{HZ}$ in patients with $\mathrm{RA}$, those without $\mathrm{HZ}$ (the control group) were matched for age, gender and RA index date with the HZ group at a ratio of 4:1, and a total of 1100 control subjects were selected. The characteristics of the enrolled participants are summarised in table 1.

Approximately $67.3 \%(\mathrm{n}=185)$ of patients with RA with $\mathrm{HZ}$ were aged over 50 years and $78.2 \%(\mathrm{n}=215)$ were female. The prevalence of comorbidities, including HT, CKD and DM $(\mathrm{p}<0.05)$, was higher in patients with RA with HZ compared with the controls. In this study, none of the patients with RA had HIV disease. Significantly higher proportions of non-steroid anti-inflammatory drugs $(77.1 \%$ vs $49.6 \%$, table 1$)$, conventional synthetic disease-modifying anti-rheumatic drugs (eg, methotrexate $(53.8 \%$ vs $19.6 \%)$, hydroxychloroquine $(74.5 \%$ vs $39.5 \%)$ and sulfasalazine $(49.1 \%$ vs $19.1 \%)$ ), corticosteroids $(88.0 \%$ vs $40.9 \%)$ and anti-TNF biologicals $(20.0 \%$ vs $6.2 \%$ ) were used in RA with HZ cases. The average time of RA disease duration at the time of $\mathrm{HZ}$ diagnosis is $10.0 \pm 4.7$ years (range $0.1-15.0$ years) (figure $1 \mathrm{~A}$ ).

Table 1 Baseline characteristics $(\mathrm{N}=1375)$

\begin{tabular}{|c|c|c|c|}
\hline & $\begin{array}{l}\text { HZ case }(n=275) \\
n(\%)\end{array}$ & $\begin{array}{l}\text { Control }(n=1100) \\
n(\%)\end{array}$ & p Value \\
\hline \multicolumn{4}{|l|}{ Age at entry, years } \\
\hline Mean $\pm S D$ & $55.3 \pm 12.7$ & $55.3 \pm 12.7$ & 1.00 \\
\hline RA disease duration & $10.0 \pm 4.7$ & $10.1 \pm 4.7$ & 0.704 \\
\hline \multicolumn{4}{|l|}{ Year } \\
\hline 20-49 & 90 (32.7\%) & 360 (32.7\%) & \\
\hline $50-64$ & $123(44.7 \%)$ & $492(44.7 \%)$ & \\
\hline$\geq 65$ & $62(22.5 \%)$ & $248(22.5 \%)$ & \\
\hline Gender & & & 0.86 \\
\hline Female & $215(78.2 \%)$ & 868 (78.9\%) & \\
\hline Male & $60(21.8 \%)$ & $232(21.1 \%)$ & \\
\hline $\mathrm{BMI}, \mathrm{kg} / \mathrm{m}^{2}$ & $23.7 \pm 4.4$ & $24.0 \pm 4.1$ & 0.535 \\
\hline Smoking history & $29(10.5 \%)$ & $85(7.7 \%)$ & 0.163 \\
\hline $\mathrm{CRP}, \mathrm{mg} / \mathrm{dL}$ & $1.75 \pm 0.58$ & $0.98 \pm 0.47$ & 0.04 \\
\hline \multicolumn{4}{|l|}{ Comorbidity } \\
\hline $\mathrm{HT}$ & $96(34.9 \%)$ & 235 (21.4\%) & $<0.001$ \\
\hline CKD & $52(18.9 \%)$ & $118(10.7 \%)$ & $<0.001$ \\
\hline DM & $42(15.3 \%)$ & $114(10.4 \%)$ & 0.03 \\
\hline Malignancies & $8(2.9 \%)$ & $50(4.5 \%)$ & 0.30 \\
\hline \multicolumn{4}{|l|}{ Medication used } \\
\hline NSAID & $212(77.1 \%)$ & $546(49.6 \%)$ & $<0.001$ \\
\hline Methotrexate & $148(53.8 \%)$ & $216(19.6 \%)$ & $<0.001$ \\
\hline Hydroxychloroquine & $205(74.5 \%)$ & 435 (39.5\%) & $<0.001$ \\
\hline Sulfasalazine & $135(49.1 \%)$ & $210(19.1 \%)$ & $<0.001$ \\
\hline Leflunomide & $13(4.7 \%)$ & $24(2.2 \%)$ & 0.03 \\
\hline Corticosteroids & $242(88.0 \%)$ & $450(40.9 \%)$ & $<0.001$ \\
\hline Anti-TNF biologicals* & $55(20.0 \%)$ & $68(6.2 \%)$ & $<0.001$ \\
\hline Non-anti-TNF biologicals $†$ & $15(5.5 \%)$ & $42(3.8 \%)$ & 0.29 \\
\hline
\end{tabular}


Figure 1 (A) The distribution of rheumatoid arthritis (RA) disease duration at the time of herpes zoster $(\mathrm{HZ})$ diagnosis. $(\mathrm{B})$ The distribution of immunosuppressive drug exposure time at the time of $\mathrm{HZ}$ diagnosis.

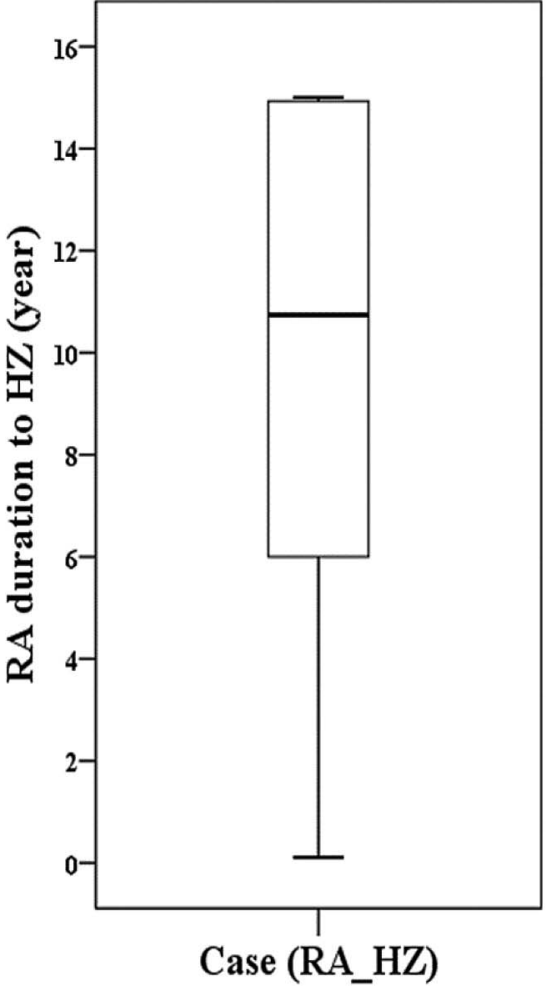

Risk of $\mathrm{HZ}$ in patients receiving different immunosuppressive medications

After full adjustment, methotrexate (adjusted OR (aOR) $=1.98,95 \%$ CI 1.43 to $2.76, \mathrm{p}<0.001$ ), hydroxychloroquine $(\mathrm{aOR}=1.95,95 \%$ CI 1.39 to $2.73, \mathrm{p}<0.001)$, sulfasalazine $(\mathrm{aOR}=1.75,95 \%$ CI 1.27 to $2.43, \mathrm{p}<0.001)$ and corticosteroids $(<5 \mathrm{mg}$ /day aOR $=1.28,95 \%$ CI 1.17 to $1.47, \mathrm{p}<0.001 ; 5$ to $<10 \mathrm{mg} /$ day $\mathrm{aOR}=1.73$, 95\% CI 1.34 to 2.32 , $\mathrm{p}<0.001 ; \geq 10 \mathrm{mg} /$ day $\mathrm{aOR}=2.30,95 \%$ CI 1.25 to 4.22 , $\mathrm{p}<0.001)$ were associated with an increased risk of $\mathrm{HZ}$ (table 2). In addition, a dose-dependent association was observed between corticosteroids and a greater OR for $\mathrm{HZ}$ ( $p_{\text {trend }}<0.001$ ) after adjustment for comorbidities (HT, CKD and $\mathrm{DM}$ ) and other immunosuppressive medication use.

Current anti-TNF biologicals users had significantly increased risk of $\mathrm{HZ}$ compared with non-users $(\mathrm{aOR}=2.07,95 \%$ CI 1.34 to $3.19, \mathrm{p}=0.001)$ (table 2). However, there was no significantly increased risk of $\mathrm{HZ}$ in patients with RA who received non-anti-TNF biologicals $(\mathrm{aOR}=1.05,95 \%$ CI 0.54 to $2.03, \mathrm{p}=0.88)$. Among anti-TNF biological users, more patients with RA with HZ had received adalimumab compared with the control cohort $(10.9 \%$ vs $2.2 \%, \mathrm{p}<0.001)$ (see online supplementary table). An increased risk of HZ in adalimumab users was detected (crude OR=5.49, 95\% CI 3.15 to $9.56, \mathrm{p}<0.001)$.

The proportion of severity and complications of HZ in patients receiving different immunosuppressive medications

In this study, the average time of drug exposure at the time of $\mathrm{HZ}$ diagnosis is $4.0 \pm 3.8$ years (range $0.1-14.8$ years) (figure 1B). All $\mathrm{HZ}$ cases who had drug exposure time more than 13 years (circle symbol, $n=8$, figure $1 \mathrm{~B}$ ) were receiving non-biologicals therapy. We further analyse the immunosuppressive drug exposure time-to-HZ diagnosis among patients with RA receiving different immunosuppressive medication (figure 2). The results showed that patients in biologicals medication groups had a shorter time period for HZ occurrence than those in the non-biologicals group. HZ occurrence time was significantly different between the biologicals and non-biologicals medication groups $(p<0.001)$, but there was no significant difference between the anti-TNF biologicals and non-anti-TNF biologicals groups $(p=0.41)$. The average time between the onset of RA identification and $\mathrm{HZ}$ occurrence was $4.0 \pm 3.8$ years (range 0.1-14.8 years, table 3); and 75 (27.3\%) patients were diagnosed with $\mathrm{HZ}$ within 1 year after RA identification. The time-to-HZ was the shortest in the non-anti-TNF biologicals group $(1.7 \pm 1.3$ years, $\mathrm{p}<0.001$, table 3$)$, followed by the anti-TNF biologicals group (2.3 \pm 2.0 years, $\mathrm{p}<0.001)$ and the non-biologicals group (4.6 \pm 4.0 years).

In this study, $154(56.0 \%)$ patients with RA with $\mathrm{HZ}$ were treated with oral antiviral medications, and 31 $(11.3 \%)$ received intravenous acyclovir (table 3). Eighty patients with RA with $\mathrm{HZ}(80 / 275,29.1 \%)$ had $\mathrm{HZ}$ complications, the most common of which was $\mathrm{HZ}$ neuralgia $(73 / 275,26.5 \%)$, followed by ophthalmic HZ $(7 / 275,2.5 \%)$. Among seven cases of RA with ophthalmic HZ, three patients had received non-anti-TNF biologicals (2 rituximab and 1 tocilizumab) medication $(\mathrm{p}<0.001)$. 
Table 2 ORs for the risk of $\mathrm{HZ}$ according to anti-rheumatic medication used in patients with rheumatoid arthritis

\begin{tabular}{|c|c|c|c|c|c|c|}
\hline & HZ case $(n=275)$ & Control $(n=1100)$ & Crude OR (95\% CI) & p Value & Adjusted* OR (95\% Cl) & p Value \\
\hline \multicolumn{7}{|l|}{ NSAID } \\
\hline Non-current use & $63(22.9 \%)$ & $554(50.4 \%)$ & 1.0 (ref.) & & 1.0 (ref.) & \\
\hline Current use & $212(77.1 \%)$ & $546(49.6 \%)$ & 3.41 (2.52 to 4.63$)$ & $<0.001$ & $1.28(0.89$ to 1.84$)$ & 0.18 \\
\hline \multicolumn{7}{|l|}{ Methotrexate } \\
\hline Non-current use & $127(46.2 \%)$ & $884(80.4 \%)$ & 1.0 (ref.) & & 1.0 (ref.) & \\
\hline Current use & $148(53.8 \%)$ & $216(19.6 \%)$ & 4.77 (3.61 to 6.31$)$ & $<0.001$ & $1.98(1.43$ to 2.76$)$ & $<0.001$ \\
\hline \multicolumn{7}{|l|}{ Hydroxychloroquine } \\
\hline Non-current use & $70(25.5 \%)$ & $665(60.5 \%)$ & 1.0 (ref.) & & 1.0 (ref.) & \\
\hline Current use & $205(74.5 \%)$ & 435 (39.5\%) & 4.48 (3.33 to 6.03$)$ & $<0.001$ & 1.95 (1.39 to 2.73$)$ & $<0.001$ \\
\hline \multicolumn{7}{|l|}{ Sulfasalazine } \\
\hline Non-current use & $140(50.9 \%)$ & $890(80.9 \%)$ & 1.0 (ref.) & & 1.0 (ref.) & \\
\hline Current use & $135(49.1 \%)$ & $210(19.1 \%)$ & 4.09 (3.09 to 5.41$)$ & $<0.001$ & 1.75 (1.27 to 2.43$)$ & $<0.001$ \\
\hline \multicolumn{7}{|l|}{ Leflunomide } \\
\hline Non-current use & $262(95.3 \%)$ & $1076(97.8 \%)$ & 1.0 (ref.) & & 1.0 (ref.) & \\
\hline Current use & $13(4.7 \%)$ & $24(2.2 \%)$ & $2.22(1.12$ to 4.43$)$ & 0.02 & $1.12(0.54$ to 2.32$)$ & 0.76 \\
\hline \multicolumn{7}{|l|}{ Corticosteroids } \\
\hline None & $33(12.0 \%)$ & $650(59.1 \%)$ & 1.0 (ref.) & & 1.0 (ref.) & \\
\hline$<5$ mg/day & $61(22.2 \%)$ & $148(13.5 \%)$ & 8.12 (5.13 to 12.86$)$ & $<0.001$ & $1.28(1.17$ to 1.47$)$ & $<0.001$ \\
\hline 5 to $<10 \mathrm{mg} /$ day & $151(54.9 \%)$ & $263(23.9 \%)$ & 11.31 (7.56 to 16.92$)$ & $<0.001$ & 1.73 (1.34 to 2.32$)$ & $<0.001$ \\
\hline$\geq 10 \mathrm{mg} /$ day & $30(10.9 \%)$ & $39(3.5 \%)$ & 15.15 (8.39 to 27.35$)$ & $<0.001$ & 2.30 (1.25 to 4.22$)$ & 0.01 \\
\hline $\bar{p}_{\text {trend }}$ & & & & $<0.001$ & & $<0.001$ \\
\hline \multicolumn{7}{|l|}{ Anti-TNF biologicals $†$} \\
\hline Non-current use & $220(80.0 \%)$ & $1032(93.8 \%)$ & 1.0 (ref.) & & 1.0 (ref.) & \\
\hline Current use & $55(20.0 \%)$ & $68(6.2 \%)$ & 3.79 (2.58 to 5.57$)$ & $<0.001$ & 2.07 (1.34 to 3.19$)$ & 0.001 \\
\hline \multicolumn{7}{|c|}{ Non-anti-TNF biologicals $\ddagger$} \\
\hline Non-current use & $260(94.5 \%)$ & 1058 (96.2\%) & 1.0 (ref.) & & 1.0 (ref.) & \\
\hline Current use & $15(5.5 \%)$ & $42(3.8 \%)$ & 1.45 (0.79 to 2.66$)$ & 0.23 & 1.05 (0.54 to 2.03$)$ & 0.88 \\
\hline
\end{tabular}

Bold text indicates that a $p$ value of $<0.05$ and considered statistically significant.

${ }^{*}$ Adjusted by comorbidities (HT, CKD and DM) and other anti-rheumatic medication use.

†ncluding adalimumab, etanercept and golimumab.

fIncluding rituximab, tocilizumab and abatacept.

CKD, chronic kidney disease; DM, diabetes mellitus; HT, hypertension; HZ, herpes zoster; NSAID, non-steroid anti-inflammatory drugs; TNF, tumour necrosis factor. 
Figure 2 Drug exposure time-to-HZ diagnosis among patients with $R A$ receiving different immunosuppressive medication treatments. $\mathrm{HZ}$, herpes zoster; RA, rheumatoid arthritis; TNF, tumour necrosis factor.

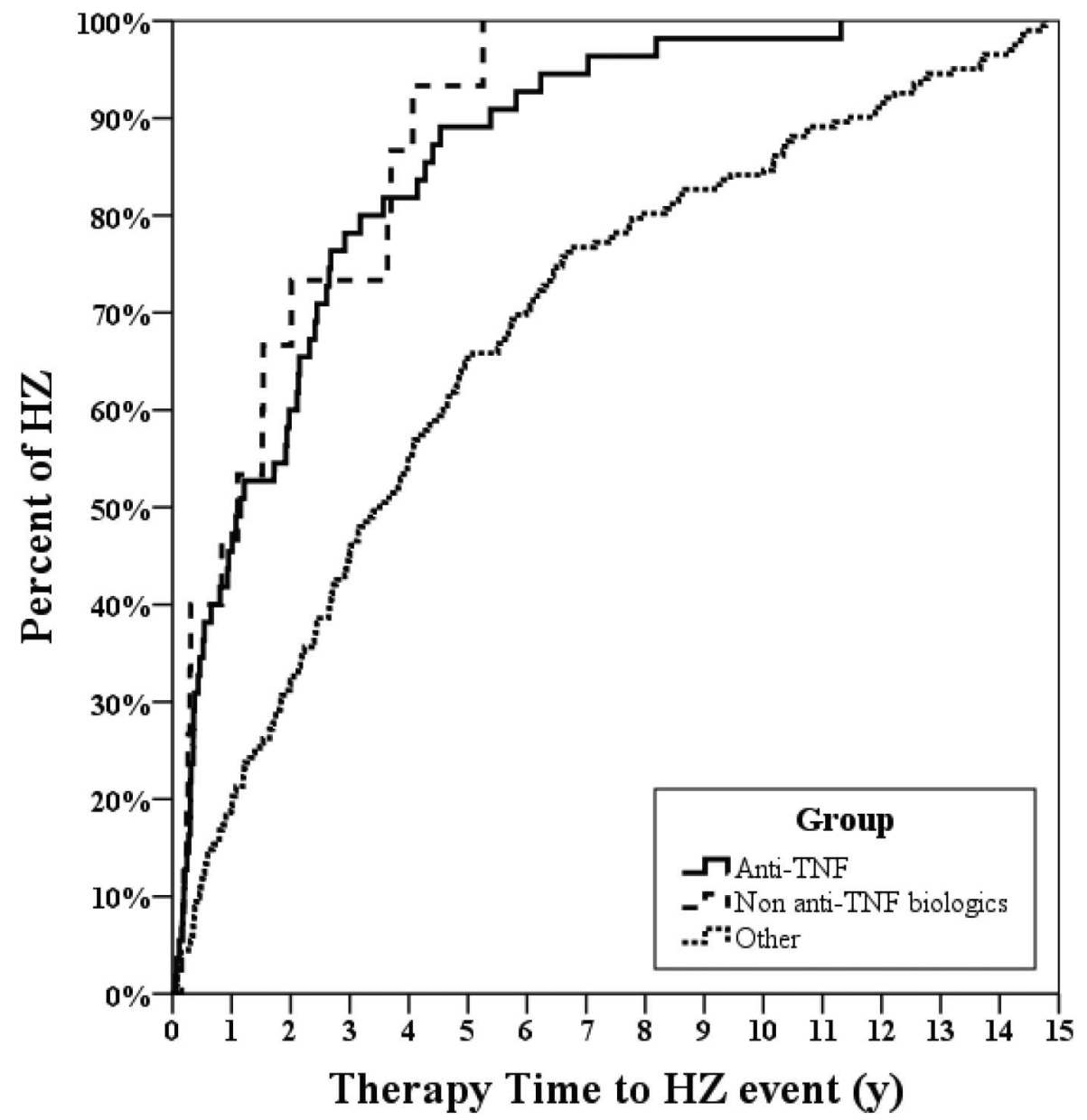

\begin{tabular}{|c|c|c|c|c|}
\hline \multirow{2}{*}{ Test method } & P for log rank & $\begin{array}{c}|c| \\
\text { Pair comparison } \\
\text { (Anti-TNF, Non } \\
\text { anti-TNF biologics) }\end{array}$ & (Anti-TNF, Other) & $\begin{array}{c}\text { (Non anti-TNF } \\
\text { biologics, Other) }\end{array}$ \\
\hline Log Rank test & $<\mathbf{0 . 0 0 1 * *}$ & 0.41 & $<\mathbf{0 . 0 0 1 * *}$ & $<\mathbf{0 . 0 0 1 * *}$ \\
\hline
\end{tabular}

Table 3 The proportion of severity and complications of $\mathrm{HZ}$ in patients with rheumatoid arthritis

\begin{tabular}{|c|c|c|c|c|c|c|c|c|c|c|}
\hline \multirow[b]{4}{*}{ Variable } & \multirow{2}{*}{\multicolumn{2}{|c|}{ All }} & \multicolumn{8}{|c|}{ Medication group } \\
\hline & & & \multirow{2}{*}{\multicolumn{3}{|c|}{$\begin{array}{l}\text { Anti-TNF biologicals* } \\
(\mathrm{N}=55)\end{array}$}} & \multirow{2}{*}{\multicolumn{3}{|c|}{$\frac{\text { Non-anti-TNF biologicals } \dagger}{(\mathrm{N}=15)}$}} & \multirow{2}{*}{\multicolumn{2}{|c|}{$\frac{\text { Non-biologicals }}{(\mathrm{N}=205)}$}} \\
\hline & \multicolumn{2}{|c|}{$\overline{(N=275)}$} & & & & & & & & \\
\hline & $\mathrm{n}$ & Per cent & $\mathrm{n}$ & Per cent & p Valueł & $\mathrm{n}$ & Per cent & p Value $\ddagger$ & $\mathrm{n}$ & Per cent \\
\hline \multicolumn{11}{|c|}{ Time-to-HZ event (years) } \\
\hline Mean $\pm S D$ & \multicolumn{2}{|c|}{$4.0 \pm 3.8$} & \multicolumn{2}{|c|}{$2.3 \pm 2.0$} & $<0.001$ & \multicolumn{2}{|c|}{$1.7 \pm 1.3$} & $<0.001$ & \multicolumn{2}{|c|}{$4.6 \pm 4.0$} \\
\hline \multicolumn{11}{|l|}{ Antiviral treatment } \\
\hline Oral & 154 & 56.0 & 37 & 67.3 & 0.086 & 8 & 53.3 & 0.798 & 109 & 53.2 \\
\hline Intravenous§ & 31 & 11.3 & 14 & 25.5 & $<0.001$ & 6 & 40.0 & $<0.001$ & 11 & 5.4 \\
\hline \multicolumn{11}{|l|}{ HZ complication } \\
\hline HZ neuralgia & 73 & 26.5 & 20 & 36.4 & 0.092 & 4 & 26.7 & 0.943 & 49 & 23.9 \\
\hline Ophthalmic HZ & 7 & 2.5 & 1 & 1.8 & 0.625 & 3ी & 20.0 & $<0.001$ & 3 & 1.5 \\
\hline \multicolumn{11}{|c|}{$\begin{array}{l}\text { Bold text indicates that a } p \text { value of }<0.05 \text { and considered statistically significant. } \\
\text { *Including adalimumab, etanercept and golimumab. } \\
\text { tIncluding rituximab, tocilizumab and abatacept. } \\
\text { †Compared with the non-biologicals group. } \\
\text { §lncluding adalimumab (11), etanercept (3), rituximab (4), tocilizumab (2), and non-biologicals (11). } \\
\text { IRituximab (2), tocilizumab (1). } \\
\text { HZ, herpes zoster; TNF, tumour necrosis factor. }\end{array}$} \\
\hline
\end{tabular}




\section{DISCUSSION}

We performed a case-control study using a hospitalbased clinical information database to investigate the association of immunosuppressive medication with HZ. Among 9025 newly diagnosed patients with RA during the period 2001-2014, we noted an increased risk of HZ in those receiving immunosuppressive medication to treat RA disease. The use of corticosteroids showed a strong dose-dependent association with $\mathrm{HZ}$ ( $\mathrm{p}_{\text {trend- }}$ $<0.001)$. Patients with RA taking specific non-biological medications (eg, methotrexate aOR=1.98, hydroxychloroquine $\mathrm{aOR}=1.95$, and sulfasalazine $\mathrm{aOR}=1.75$ ) were similar or slightly less prone to develop HZ than patients taking anti-TNF biological medications $(\mathrm{aOR}=2.07)$. Furthermore, patients in biologicals medication groups had a shorter time period for HZ occurrence than those in the non-biologicals group $(\mathrm{p}<0.001)$. A higher incidence of severe HZ (11.3\%) was found in our RA cohort. The use of biologicals was associated with an increased risk of severe $\mathrm{HZ}$ and ophthalmic involvement.

Serious infections are a major concern in patients with RA and result in increased mortality. ${ }^{22}$ An increased risk of infections in patients with RA may be associated with RA-related immunological dysfunctions, immunocompromising comorbidities and immunosuppressive agent-related immunosuppressive effects. ${ }^{23}{ }^{24}$ Several comorbidities (eg, HT, CKD, DM and malignancy) have been shown to lead to an increased risk of developing $\mathrm{HZ}$ in patients with RA, which associated with disease-related immunocompromisation or therapeutic treatment, causes a reduction in cellular immunity. ${ }^{25-27}$ In this study, our patients with RA with $\mathrm{HZ}$ also had a higher prevalence of HZ-related comorbidities (eg, HT, CKD and DM, p $<0.05$ ) as did other population-based studies in western countries. ${ }^{10}{ }^{25}$ Previous published literature had shown that HT, CKD and DM were associated with increased risk $\mathrm{HZ},{ }^{28}$ which may be due to disease-related immune dysfunction or the effects of therapeutic agents.

Glucocorticoids are potent immunosuppressive drugs that are widely used in rheumatic diseases care. ${ }^{29}$ Dixon et $a l^{30}$ showed that glucocorticoids therapy is associated with serious infection risks in older patients with RA, which particularly in current and recent doses have the greatest impact on infection risk. ${ }^{31}$ Our results showed an increased risk of $\mathrm{HZ}$ in patients with RA using corticosteroids $\quad(<5 \mathrm{mg} /$ day $\quad \mathrm{aOR}=1.28$ vs $\quad \geq 10 \mathrm{mg} /$ day $\mathrm{aOR}=2.30$, $\left.\mathrm{p}_{\text {trend }}<0.001\right)$; this was consistent with previous studies in western countries. ${ }^{10-15}$ We thought the risk of $\mathrm{HZ}$ should be associated with the severity of the RA disease and glucocorticoids-related immunosuppressive effects. In addition to corticosteroids, we also found that several non-biological medications (eg, methotrexate $\mathrm{aOR}=1.98$, hydroxychloroquine $\mathrm{aOR}=1.95$, and sulfasalazine $\mathrm{aOR}=1.75$ ) were associated with the risk of $\mathrm{HZ}$ in patients with RA; this had also been noted in studies in the USA and Europe. ${ }^{10-14}$
In addition, our results showed that the use of anti-TNF biologicals in patients with RA was associated with an increased risk of $\mathrm{HZ}(\mathrm{aOR}=2.07,95 \%$ CI 1.34 to 3.19) compared with non-users. Since TNF plays a critical role in the control of viral infection, the depletion of TNF by treatment with anti-TNF biologicals might facilitate the development or reactivation of viral infection. ${ }^{31}{ }^{32}$ Furthermore, the drug exposure time-to-HZ in patients receiving anti-TNF biological medications was shorter than that in those using non-biological medications $(2.3 \pm 2.0$ vs $4.6 \pm 4.0$ years, $\mathrm{p}<0.001)$. Our data showed that the risk of $\mathrm{HZ}$ was greatest soon after initiating anti-TNF therapy. A similar result has also been found in the UK. ${ }^{14}$

Among anti-TNF biologicals users, a higher ratio of patients with RA with $\mathrm{HZ}$ received adalimumab compared with control subjects $(10.9 \%$ vs $2.2 \%, \mathrm{p}<0.001)$. In addition, we found an increased risk of $\mathrm{HZ}$ in adalimumab users (crude OR=5.49, 95\% CI 3.15 to 9.56, $\mathrm{p}<0.001$ ), compared with non-users (see online supplementary table). Another study in Germany also found that only treatment with monoclonal anti-TNF antibodies (adalimumab or infliximab) was associated with an increased risk of $\mathrm{HZ}$ in patients with RA $(\mathrm{HR}=1.82,95 \%$ CI 1.05 to $3.15, \mathrm{p}=0.03)$; there was no association with the TNF receptor fusion protein (etanercept $) \quad(\mathrm{HR}=1.36,95 \%$ CI 0.73 to $2.55, \mathrm{p}=0.33) .{ }^{14}$ Since immunosuppression-related cellular immunity decline is known to trigger reactivation of VZV, we thought some characteristics of adalimumab (eg, high TNF binding avidity, slow dissociation and long serum

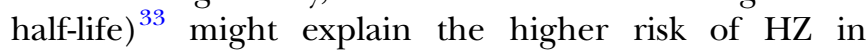
patients with RA receiving adalimumab, compared with those receiving etanercept. In addition, golimumab was not available until mid-2012 in Taiwan. Therefore, the numbers of golimumab user was less than etanercept, which may cause that patients prescribed golimumab seem not have higher risk compared with etanercept in this study. The confirmation is required from further large and long-term studies.

In accordance with intravenous antiviral medications used for HZ, it is worth noting that our results showed that the incidence of severe $\mathrm{HZ}$ was higher compared with a previous RA cohort study in the USA $(11.3 \%$ vs $4.6 \%) .{ }^{12}$ Most patients with RA with HZ complications were aged more than 50 years $(93.8 \%)$ and female $(83.8 \%)$, which was consistent with the results in the general population. ${ }^{6}{ }^{34}$ Regarding the complications of $\mathrm{HZ}$, the incidence of PHN was higher in our RA cohort compared with patients with RA in the USA $(26.5 \%$ vs $19.1 \%) .{ }^{12}$ In addition, our results showed that the incidence of severe $\mathrm{HZ}$ was higher in patients with RA receiving biologicals, compared with those in the nonbiologicals group (anti-TNF, 25.5\% vs 5.4\%, p $<0.001$; non-anti-TNF, $40.0 \%$ vs $5.4 \%$, p $<0.001$ ). Serious morbidity and mortality from VZV infection has been reported in patients receiving anti-TNF biologicals therapy in the USA, Europe and Korea. ${ }^{35}$ Most cases were receiving 
infliximab, followed by etanercept and adalimumab. ${ }^{35} \mathrm{~A}$ study in Israel found anti-TNF biologicals to be associated with an increased HZ risk (HR=2.73, 95\% CI 1.58 to 4.70$)$, as well as related to PHN occurrence $\left(\mathrm{HR}=2.95,95 \%\right.$ CI 0.41 to 21.06). ${ }^{36}$ In Taiwan, infliximab is not approved. In this study, the incidence of PHZ tended to increase with anti-TNF biologicals treatment, compared with non-biologicals treatment $(36.4 \%$ vs $23.9 \%$ ), but this increase was not statistically significant $(\mathrm{p}=0.092)$. We thought that the decrease in statistical power might be associated with the small case numbers in this study, and confirmation is required from further larger studies. In addition to PHN, ophthalmic HZ is another common HZ complication. Until now, most published ophthalmic HZ studies are case reports ${ }^{37}$ and little is known about the risk factors of ophthalmic HZ in patients with RA. Our results demonstrated a trend towards a higher proportion of ophthalmic $\mathrm{HZ}$ in patients receiving therapy with non-TNF biologicals (rituximab/tocilizumab), compared with non-biologicals $(20.0 \%$ vs $1.5 \%, \mathrm{p}<0.001)$. The above observations suggest a higher risk of severe HZ in patients with RA receiving biological therapy.

This study has several limitations. First, the immunosuppressive medication-related individual rheumatic disease activity data was lacking. In our databases, a total of $52 \mathrm{HZ}$ cases had a measurement of 28-joint disease activity score (DAS28) at the time of HZ, and the average of the score was higher (4.54 \pm 1.27$)$ and had an active status. In addition, a significantly higher $\mathrm{C}$ reactive protein (CRP) was shown in HZ cases $(1.75 \pm 0.58 \mathrm{mg}$ / $\mathrm{dL})$, compared with that in controls $(0.98 \pm 0.47 \mathrm{mg} / \mathrm{dL}$, $\mathrm{p}=0.04)$. On the basis of our results, we thought uncontrolled RA disease itself would render one more prone to HZ. In addition, the British Society for Rheumatology guidelines requested that patients with RA had a DAS28 $>5.1$ (severe RA) then started biological therapy. ${ }^{20}$ In this study, among $70 \mathrm{HZ}$ cases with biologicals treatment, only $53(75.7 \%)$ were first-time used, while the other $17(24.3 \%)$ were had other biologics use history. Therefore, we thought that patients with more severe RA may be more likely to use biologicals and a higher dosage of corticosteroids for more intensive therapy. Therefore, we estimated the severity of RA maybe as a risk factor for HZ. Further studies are required to confirm. Second, the validation of antiviral treatment in the outpatients department cannot be fully confirmed. Although only $185(67.3 \%)$ of the patients with RA with $\mathrm{HZ}$ received antiviral therapy, most patients without an antiviral treatment record in our database received HZ medication in nearby clinics. Therefore, we may have underestimated the risk of HZ. In addition, the real vaccination information is not available completely. In Taiwan, zoster vaccine was available since October 2013. In our database, there were only two patients in the control group who had zoster vaccination. All $\mathrm{HZ}$ cases had not had zoster vaccination before HZ. Third, this study was conducted at a single medical centre and included a small number of cases; consequently, it is likely that the study cannot reflect the complete characteristics of $\mathrm{HZ}$ in patients with RA. However, to the best of our knowledge, this is the first long-term case-control study to describe an association between immunosuppressive drugs and $\mathrm{HZ}$ in Asian patients with RA after controlling for several potential confounders, and the first study to investigate the relationship between biologicals and severe $\mathrm{HZ}$ in Asia. Finally, the matched control cohort may have a selection bias. Nevertheless, we analysed data from a clinical information database and reviewed medical care records to identify patients with RA with HZ, so we believe that it is only slightly affected by selection and recall biases. The major strength of this study is the use of long-term medical records. A 14-year follow-up period (2001-2014) enhanced the statistical power and accuracy of this study. We believe this study provides useful information that can help increase the awareness of physicians in assessing the possibility and outcomes of $\mathrm{HZ}$ in patients with RA during the period of specific immunosuppressive medication therapy.

In conclusion, although it is difficult to distinguish the risks conferred by immunosuppressive drugs from disease activity among patients with RA, our data showed an increased risk of $\mathrm{HZ}$ in patients with RA with several immunosuppressive medications, particularly when using corticosteroids. The incidence of severe $\mathrm{HZ}$ among patients with RA in Asia was higher than that in the USA ( $11.3 \%$ vs $4.6 \%)$. Biologicals were associated with severe $\mathrm{HZ}$ occurrence and the risk of $\mathrm{HZ}$ was greatest soon after initiating biologicals therapy. A higher incidence of $\mathrm{HZ}$ complications in patients with RA was found in this study. Therefore, it is important to closely monitor the occurrence of $\mathrm{HZ}$ in patients with RA during immunosuppressive therapy and start immediate efficient antiviral treatment to prevent the development of severe complications.

\section{Author affiliations}

${ }^{1}$ Department of Medical Research, Taichung Veterans General Hospital, Taichung, Taiwan

${ }^{2}$ Rong Hsing Research Center for Translational Medicine, National Chung Hsing University, Taichung, Taiwan

${ }^{3}$ Division of Allergy, Immunology and Rheumatology, Taichung Veterans General Hospital, Taipei, Taiwan

${ }^{4}$ Faculty of Medicine, National Yang Ming University, Taipei, Taiwan ${ }^{5}$ Department of Medical Education, Taichung Veterans General Hospital, Taichung, Taiwan

${ }^{6}$ Institute of Biochemistry, Microbiology and Immunology, Chung Shan Medical University, Taichung, Taiwan

Acknowledgements The authors would like to thank the Clinical Information Research and Development Center of Taichung Veterans General Hospital (Taichung, Taiwan, ROC) for kindly providing clinical information support. In addition, they thank the Biostatistics Task Force of Taichung Veterans General Hospital (Taichung, Taiwan, ROC) for kindly providing statistical analysis support. 
Contributors D-YC conceived of the study, generated the original hypothesis, designed the study, analysed the data, and drafted and revised the manuscript. T-LL designed the study, analysed the data, and drafted and revised the manuscript. Y-MC and H-JL conceived of the study, analysed the data, and drafted and revised the manuscript.

Funding This research received no specific grant from any funding agency in the public, commercial or not-for-profit sectors.

Competing interests None declared.

Ethics approval The Institutional Review Board of Taichung Veterans General Hospital.

Provenance and peer review Not commissioned; externally peer reviewed.

Data sharing statement No additional data are available.

Open Access This is an Open Access article distributed in accordance with the Creative Commons Attribution Non Commercial (CC BY-NC 4.0) license which permits others to distribute, remix, adapt, build upon this work noncommercially, and license their derivative works on different terms, provided the original work is properly cited and the use is non-commercial. See: http:// creativecommons.org/licenses/by-nc/4.0/

\section{REFERENCES}

1. Arvin A. Aging, immunity, and the varicella-zoster virus. $N$ Engl J Med 2005;352:2266-7.

2. Schmader K. Herpes zoster in older adults. Clin Infect Dis 2001;32:1481-6.

3. Thomas SL, Hall AJ. What does epidemiology tell us about risk factors for herpes zoster? Lancet Infect Dis 2004;4:26-33.

4. Nagasawa K, Yamauchi $\mathrm{Y}$, Tada $\mathrm{Y}$, et al. High incidence of herpes zoster in patients with systemic lupus erythematosus: an immunological analysis. Ann Rheum Dis 1990;49:630-3.

5. Weller TH. Varicella and herpes zoster. Changing concepts of the natural history, control, and importance of a not-so-benign virus. N Engl J Med 1983;309:1434-40.

6. Gilden DH, Kleinschmidt-DeMasters BK, LaGuardia JJ, et al Neurologic complications of the reactivation of varicella-zoster virus. N Engl J Med 2000;342:635-45.

7. Hobbelen PH, Stowe J, Amirthalingam G, et al. The burden of hospitalisation for varicella and herpes zoster in England from 2004 to 2013. J Infect 2016;73:241-53.

8. Greenberg JD, Reed G, Kremer JM, et al. Association of methotrexate and tumour necrosis factor antagonists with risk of infectious outcomes including opportunistic infections in the CORRONA registry. Ann Rheum Dis 2010;69:380-6.

9. Doran MF, Crowson CS, Pond GR, et al. Frequency of infection in patients with rheumatoid arthritis compared with controls: a population-based study. Arthritis Rheum 2002;46:2287-93.

10. Smitten AL, Choi HK, Hochberg MC, et al. The risk of herpes zoster in patients with rheumatoid arthritis in the United States and the United Kingdom. Arthritis Rheum 2007:57:1431-8.

11. McDonald JR, Zeringue AL, Caplan L, et al. Herpes zoster risk factors in a national cohort of veterans with rheumatoid arthritis. Clin Infect Dis 2009:48:1364-71.

12. Veetil BM, Myasoedova E, Matteson EL, et al. Incidence and time trends of herpes zoster in rheumatoid arthritis: a population-based cohort study. Arthritis Care Res (Hoboken) 2013;65:854-61.

13. Strangfeld A, Listing J, Herzer $P$, et al. Risk of herpes zoster in patients with rheumatoid arthritis treated with anti-TNF-alpha agents. JAMA 2009;301:737-44.

14. Galloway JB, Mercer LK, Moseley A, et al. Risk of skin and soft tissue infections (including shingles) in patients exposed to anti-tumour necrosis factor therapy: results from the British Society for Rheumatology Biologics Register. Ann Rheum Dis 2013;72:229-34
15. Winthrop KL, Baddley JW, Chen L, et al. Association between the initiation of anti-tumor necrosis factor therapy and the risk of herpes zoster. JAMA 2013;309:887-95.

16. Kawai K, Gebremeskel BG, Acosta CJ. Systematic review of incidence and complications of herpes zoster: towards a global perspective. BMJ Open 2014;4:e004833

17. Nakajima A, Urano W, Inoue $\mathrm{E}$, et al. Incidence of herpes zoster in Japanese patients with rheumatoid arthritis from 2005 to 2010. Mod Rheumatol 2015;25:558-61.

18. Arnett FC, Edworthy SM, Bloch DA, et al. The American Rheumatism Association 1987 revised criteria for the classification of rheumatoid arthritis. Arthritis Rheum 1988;31:315-24.

19. British Society for Rheumatology. Guidelines for prescribing $T N F-\alpha$ blockers in adults with rheumatoid arthritis. London: British Society for Rheumatology, 2001 (http://www.rheumatology.org.uk)

20. Ledingham J, Deighton C, British Society for Rheumatology Standards, Guidelines and Audit Working Group. Update on the British Society for Rheumatology guidelines for prescribing TNFalpha blockers in adults with rheumatoid arthritis (update of previous guidelines of April 2001). Rheumatology (Oxford) 2005;44:157-63.

21. Brode SK, Jamieson $\mathrm{FB}, \mathrm{Ng} \mathrm{R}$, et al. Increased risk of mycobacteria infections associated with anti-rheumatic medications. Thorax 2015;70:677-82.

22. Cobb S, Anderson F, Bauer W. Length of life and cause of death in rheumatoid arthritis. N Engl J Med 1953;249:553-6.

23. Listing J, Gerhold K, Zink A. The risk of infections associated with rheumatoid arthritis, with its comorbidity and treatment. Rheumatology (Oxford) 2013;52:53-61.

24. Davies R, Symmons DPM, Hyrich KL. Biologics registers in rheumatoid arthritis. Medicine (Baltimore) 2014;42:262-5.

25. Forbes HJ, Bhaskaran K, Thomas SL, et al. Quantification of risk factors for herpes zoster: population based case-control study. BMJ 2014;348:g291.

26. Johnson SL, Bartels CM, Palta M, et al. Biological and steroid use in relationship to quality measures in older patients with inflammatory bowel disease: a US Medicare cohort study. BMJ Open 2015;5: e008597.

27. Joesoef RM, Harpaz R, Leung J, et al. Chronic medical conditions as risk factors for herpes zoster. Mayo Clin Proc 2012;87:961-7.

28. Hata A, Kuniyoshi M, Ohkusa Y. Risk of Herpes zoster in patients with underlying diseases: a retrospective hospital-based cohort study. Infection 2011;39:537-44

29. Caplan L, Wolfe F, Russell AS, et al. Corticosteroid use in rheumatoid arthritis: prevalence, predictors, correlates, and outcomes. J Rheumatol 2007;34:696-705.

30. Dixon WG, Abrahamowicz M, Beauchamp ME, et al. Immediate and delayed impact of oral glucocorticoid therapy on risk of serious infection in older patients with rheumatoid arthritis: a nested case-control analysis. Ann Rheum Dis 2012;71:1128-33.

31. Guidotti LG, Chisari FV. Noncytolytic control of viral infections by the innate and adaptive immune response. Annu Rev Immunol 2001;19:65-91.

32. Lane MA, McDonald JR, Zeringue AL, et al. TNF-alpha antagonist use and risk of hospitalization for infection in a national cohort of veterans with rheumatoid arthritis. Medicine (Baltimore) 2011;90:139-45.

33. Nestorov I. Clinical pharmacokinetics of TNF antagonists: how do they differ? Semin Arthritis Rheum 2005;34:12-18.

34. Kawai K, Rampakakis E, Tsai TF, et al. Predictors of postherpetic neuralgia in patients with herpes zoster: a pooled analysis of prospective cohort studies from North and Latin America and Asia. Int J Infect Dis 2015;34:126-31.

35. Kim SY, Solomon DH. Tumor necrosis factor blockade and the risk of viral infection. Nat Rev Rheumatol 2010;6:165-74.

36. Weitzman $D$, Shavit $O$, Stein $M$, et al. A population based study of the epidemiology of Herpes Zoster and its complications. J Infect 2013;67:463-9.

37. Yawn BP, Wollan PC, St Sauver JL, et al. Herpes zoster eye complications: rates and trends. Mayo Clin Proc 2013;88:562-70. 